\title{
Design Centrado no Usuário e concepções pedagógicas como guia para o desenvolvimento da animação educacional
}

\author{
User-centered Design and pedagogical concepts to \\ guide the development of educational animation
}

\author{
Marcia Maria Alves, André Luiz Battaiola
}

Animação, educação, DCU

\begin{abstract}
A produção de animações gráficas para o ensino fundamental tem se proliferado devido às tecnologias de comunicação e à necessidade de novos recursos que auxiliem ao aprendizado. No entanto, muitas animações são apenas reproduções do material impresso, sem um uso adequado da tecnologia, sem uma adaptação para o aluno/usuário e não alinhadas às concepções pedagógicas atuais. Este artigo pretende buscar na literatura bases para um procedimento de elaboração de materiais didáticos (animações gráficas) conectado às concepções construtivistas por meio da aplicação dos princípios do Design Centrado no Usuário (DCU). Para isso, os autores apresentam revisão bibliográfica, comparam os princípios das concepções construtivistas de Vygotsky e do DCU, e indicam um possível processo de Design que pode auxiliar na confecção de animações gráficas mais engajadas nas linhas construtivistas e mais próximas dos alunos.
\end{abstract}

Animation, education,

The production of graphic animation for elementary school has proliferated due to UCD new communication technologies and the need for new resources to aid the learning. However, many animations are just reproductions of printed material, without an appropriate use of technology, unadjusted for the student / user and, not in line with current pedagogical concepts. This paper aims to search in literature the basis for a procedure to design instructional materials (graphic animation) connected to constructivist conceptions by applying User-Centered Design (UCD) principles. With this goal, the authors presents a literature review, compares Vygotsky's principles and $U C D$, and indicating a possible design process that can help making learning animation more engaged with constructivist approaches and closer to the students.

\section{Introdução}

A produção de animações para aprendizagem tem se expandido devido às facilidades tecnológicas advindas dos novos sistemas de informação, representação gráfica e comunicação social (BARBOSA JÚNIOR, 2005). 
1 Entende-se aprendizado significativo (termo criado pelo pesquisador David Ausubel) que a aprendizagem só acontece definitivamente quando existe um significado relevante no conteúdo, e este é percebido pelo aprendiz. Isso faz com que o aprendiz seja capaz de lidar com o conhecimento mesmo em circunstâncias mais diversas e associá-lo a repertórios próprios (MOREIRA, 2006).
O design dessas animações tem como base, conteúdos e formatos voltados para as questões de ensino e, como objetivo, a transmissão de conteúdos.

Diversas pesquisas mostram as animações educacionais como auxiliares ao ensino. Tais quais as imagens estáticas, elas agregam conteúdos visuais e interfaces com as vantagens de configuração do tempo e do movimento, além de serem atrativas e de possuírem mais elementos (linguagem sonora, visual e verbal) que podem ser configurados (LOWE \& SCHNOTZ, 2008; AINSWORTH, 2008).

O aprendizado depende da percepção, da compreensão da interface e da informação, assim como de fatores cognitivos, sociais e culturais. No entanto, ao enfocar o conteúdo, muitas vezes esses objetos se esquecem da recepção, interpretação, interação e assimilação deste conteúdo pelos aprendizes, ou seja, não levam em consideração que este projeto pode ser pensado com base nos de estudos em Design da informação. Além do Design, é necessário também considerar as perspectivas e concepções que estão envolvidas na geração do material.

As concepções de ensino interacionistas, dentre elas o construtivismo, têm como base a participação ativa do aluno no processo de aprendizagem, pois acreditam que, conforme Sant'anna e Sant'anna (2004. p. 10) a "participação passiva bloqueia qualquer tipo de desenvolvimento, seja individual, psicológico, social ou cultural, sendo indispensável uma busca de conhecimento de forma dinâmica, interativa em que hábitos, habilidades, crenças, sejam definidos como formação humana".

O construtivismo pensa seus aprendizes não como receptáculos de conhecimento, mas como agentes ativos capazes de estruturar seus próprios conhecimentos (SANT'ANNA \& SANT'ANNA, 2004, p. 44). Com este propósito, essa concepção busca promover a autonomia do aprendiz, a colaboração, a interação com o objeto e o aprendizado significativo'.

As perguntas que movem esta pesquisa consistem em: "quais as relações entre o Design centrado no usuário (DCU) e as novas concepções pedagógicas? O DCU pode auxiliar no projeto de animações que proporcionem a aprendizagem significativa proposta pelo construtivismo?" Estabelecido este objetivo, o tópico 2 descreve a conceituação do Socioconstrutivismo de Vygotsky (FILATRO, 2008) e os princípios de DCU conforme Maguire (2001). Esses dois eixos teóricos apresentam visões e contextos distintos de análise. O DCU trabalha com contextos específicos de utilização ou realização de tarefas, e o construtivismo, sendo mais amplo, trabalha com contextos psicológicos, sociais e culturais que envolvem os alunos. O que aqui se propõe é a utilização de técnicas e conceitos do DCU para tentar desvendar, ao menos na parte relacionada ao uso da animação, os contextos que estão ali envolvidos e melhorar as animações gráficas para alunos e professores. O tópico 3 apresenta uma possível proposta de aplicação do DCU como opção para o projeto de animações 
educacionais. Por fim, têm-se as considerações finais e trabalhos futuros.

Neste contexto, este artigo tem objetivo exploratório e busca desenvolver um procedimento de concepção de animações educacionais com base nos princípios do Design Centrado no Usuário (DCU), para estabelecer maior aderência conceitual e prática com as concepções de ensino e com os aprendizes. Assim, a estratégia de pesquisa deste trabalho foi uma revisão bibliográfica que permitiu a análise dos princípios construtivistas de ensino/aprendizagem e dos princípios do Design Centrado no Usuário.

A investigação se pauta no estudo de princípios gerais dos campos pesquisados por considerá-los, conforme Goodwin (2009), como diretrizes para criar soluções adequadas em circunstâncias específicas. Esses princípios atuam como linhas de pensamento e direção que guiam estes campos e os caracteriza.

\section{Concepções pedagógicas e o Design Centrado no Usuário: conceitos e princípios}

As tecnologias e os avanços científicos trouxeram novos recursos e novos contextos para a sala de aula que necessitam de estudo. Fontoura (2002) propõe que "os avanços no campo da psicologia cognitiva, as contribuições do construtivismo, entre outras, implicaram numa série de novas competências a serem desenvolvidas pela escola." (FONTOURA, 2002, p. 7). Tais competências modificaram formas de ensino e revelaram a necessidade de novos suportes e recursos auxiliares ao aprendizado.

O construtivismo e todas as linhas a ele associadas (construcionismo, aprendizagem significativa, aprendizagem situada, tangencial) trouxeram perspectivas novas à educação. Com o construtivismo, "o conhecimento sob este ponto de vista é algo temporário, em constante desenvolvimento, não objetivo, construído internamente e é resultado da interação do indivíduo com outros, com o meio ambiente, com os objetos que o cerca, com a sua cultura e com a sociedade que pertence" (FONTOURA, 2002, p. 37).

Por meio das concepções progressistas o ensino não é mais algo unilateral, mas sim, compartilhado e construído. Assim como propõe Paulo Freire (1996) em sua Pedagogia da Autonomia, não existiria o ensinar mas, sim, o aprender e o educador precisa criar situações de aprendizado adotando o papel de mediador.

Filatro (2008, p. 14-15) apresenta um quadro comparativo entre as teorias que fundamentam o Design instrucional, onde define quatro concepções em que se apoiam as práticas da educação a distância - EAD - (comportamentalista, construtivista individual, social e situada). Essas concepções não se aplicam somente a EAD, mas são a base para a educação presencial e constituem tendência para o planejamento educacional atual. 
O quadro 1 resume a proposta de Filatro (2008). Neste quadro foi feito um recorte que apresenta somente as duas abordagens que são essenciais a este artigo (optou-se por suprimir as colunas onde se conceituava o comportamentalismo e a aprendizagem situada por não fazerem parte do escopo desta pesquisa):

Quadro 1 Caracteristicas das abordagens construtivistas

(Fonte: Adaptado de Filatro (2008, p. 14-15))

\begin{tabular}{|c|c|c|}
\hline & Construtivistas (individual) & Construtivistas (social) \\
\hline Teoria & $\begin{array}{l}\text { Aprendizado pela exploração do mundo. } \\
\text { Inputs do ambiente e integração dos } \\
\text { conhecimentos e habilidades pelo aluno. }\end{array}$ & $\begin{array}{l}\text { Descoberta individual apoiada pelo ambiente } \\
\text { social. } \\
\text { O Socioconstrutivismo se preocupa com o modo } \\
\text { como conceitos e habilidades emergentes são } \\
\text { apoiados pelos outros alunos. } \\
\text { Atividades colaborativas. }\end{array}$ \\
\hline Teóricos-chave & Piaget & Vygotsky \\
\hline $\begin{array}{l}\text { Implicações para } \\
\text { aprendizagem }\end{array}$ & $\begin{array}{l}\text { Construção ativa e integração de conceitos. } \\
\text { Problemas pouco estruturados. } \\
\text { Oportunidades para a reflexão. } \\
\text { Domínio da tarefa. }\end{array}$ & $\begin{array}{l}\text { Atividades colaborativas. } \\
\text { Problemas pouco estruturados. } \\
\text { Oportunidades para discussão e reflexão. } \\
\text { Domínio compartilhado da tarefa. }\end{array}$ \\
\hline $\begin{array}{l}\text { Implicações para o } \\
\text { ensino }\end{array}$ & $\begin{array}{l}\text { Ambientes interativos e desafios apropriados. } \\
\text { Encorajamento a experimentação. } \\
\text { Adaptação de conceitos existentes. } \\
\text { Treinamento e modelagem de } \\
\text { habilidades metacognitivas. }\end{array}$ & $\begin{array}{l}\text { Ambientes colaborativos e desafios apropriados. } \\
\text { Encorajamentos a experimentação. } \\
\text { Foco em conceitos e habilidades existentes. } \\
\text { Modelagem de habilidades, inclusive sociais. }\end{array}$ \\
\hline $\begin{array}{l}\text { Implicações para a } \\
\text { avaliação }\end{array}$ & $\begin{array}{l}\text { Compreensão conceitual. } \\
\text { Desempenho estendido. } \\
\text { Processos e resultados. } \\
\text { Certificação. } \\
\text { Auto-avaliação: autonomia. }\end{array}$ & $\begin{array}{l}\text { Compreensão conceitual. } \\
\text { Desempenho estendido. } \\
\text { Processos, participação e resultados. } \\
\text { Certificados variados. } \\
\text { Avaliação por pares e } \\
\text { responsabilidade compartilhada. }\end{array}$ \\
\hline Principais diferenças & $\begin{array}{l}\text { Tarefas de aprendizagem mais formalmente } \\
\text { estruturadas }\end{array}$ & Contextos de aprendizagem mais autênticos. \\
\hline
\end{tabular}

O quadro 1 expõe os principais objetivos das linhas construtivistas. A última linha desta tabela identifica uma mudança conceitual importante, uma quebra de paradigma quanto à estrutura das atividades de aprendizagem. De início, com o comportamentalismo, as atividades deveriam ser formalmente estruturadas e os resultados deveriam ser exatos, com base em ação-reação utilizando problemas bem definidos e respostas exatas. Com Piaget o foco passou para o indivíduo/aprendiz e a estrutura das tarefas eram direcionadas pelas características e estágios de maturação de cada faixa etária, valorizando o indivíduo, mas, ainda assim, considerando pouco o contexto. Este "contexto" vai ser incorporado no socioconstrutivismo. Com isso o ambiente e todas as interferências externas ao 
aprendiz podem constituir suas experiências e seu aprendizado (FILATRo, 2008).

Segundo Fontoura (2002), as concepções com base construtivistas propõem o seguinte:

A visão construtivista sugere que a aprendizagem ocorre através da realização de experiências concretas e significativas dentro de contextos bem definidos. Estas experiências permitem então, a construção de modelos mentais, o desenvolvimento de ideias, concepções, conceitos e estratégias pessoais. O discurso, a atividade e a reflexão são constantes nesta visão. Ela explora os processos cognitivos do indivíduo. (FONTOURA, 2002, p. 38).

Já no socioconstrutivismo e seus desdobramentos (baseados nas teorias de Vygotsky e conforme Filatro (2008)) espera-se não só uma análise do indivíduo, mas, também, dos contextos em que os aprendizes estão inseridos. Nesta linha os contextos (sociais, culturais, históricos, econômicos) colaboram e auxiliam na formação de situações aprendizagens e dos aprendizes.

Neste ponto, surge a necessidade de analisar o contexto das experiências de aprendizagem e as necessidades dos aprendizes. Por isso, se questiona o papel dos materiais construídos, pois, a partir daqui, agrega-se a função de mediação aos recursos utilizados para o aprendizado. A importância e a responsabilidade dos recursos se ampliam, pois, eles ajudarão no processo de aprendizagem.

Todas essas mudanças vêm sendo gradativamente incorporadas nas salas de aula. No entanto, para Kenski (2007, p. 45), a entrada da tecnologia ampliou as possibilidades de apresentação dos conteúdos, mas, esse processo ainda não foi o suficiente para mudar as relações dentro da maioria das salas de aula. Por mais que as escolas usem os computadores e a Internet, em muitas situações as aulas continuam iguais, expositivas, lineares e fragmentadas. Por isso, se faz necessário este entendimento do contexto e se procura alternativas para melhor projetar a informação tendo em vista o alcance e a potencialização dessas práticas no ambiente escolar.

Tendo definido as funções desses materiais dentro das linhas de pesquisa e o anseio das concepções construtivistas pelo contexto, passa-se para as questões de configuração destes materiais e aí se propõe a discussão de metodologias advindas da área do Design.

O conceito de Design é amplo e marcado pela relação com que cada autor estabelece com o campo (BRAGA, 2011). Löbach (2001) define o Design Industrial como um processo de adaptação dos produtos de uso, fabricados industrialmente, às necessidades físicas e psíquicas dos usuários ou grupo de usuários. O Design Gráfico seria a parte do Design cuja ênfase está na transmissão de mensagens e de informações por meio de configurações visuais e gráficas. Assim, o designer atuaria como um articulador e enformador de mensagens (FLUSSER, 2007). 
Pesquisas mostram que as aplicações de processos e metodologias de Design na Educação têm se multiplicado nas universidades tornando mais estável a aproximação entre estas duas áreas (FONTOURA, 2002; BRAGA, 2011; PORTUGAL, 2013).

Conforme Coutinho e Lopes (in BRAGA, 2011) ao aproximar Educação e o Design se discute, principalmente, as questões projetuais e de solução de problemas. Estas são inerentes à atividade prática do designer enquanto configurador de artefatos dentro de uma cultura material. Ainda para estas autoras, existe a necessidade de um alinhamento de saberes para a construção de pessoas capazes de lidar com as linguagens advindas das tecnologias. Uma das formas de alinhamento do Design com a Educação seria na criação de material e de artefatos, neste caso, envolvendo o Design da Informação que vai dar a forma ou representar o conteúdo.

Para Portugal e Couto (2010, p. 2 e 18) o Design "pode contribuir efetivamente para a criação de artefatos educacionais e invenções culturais, aspectos importantes no desenvolvimento cognitivo do ser humano". Proposta essa que vai ao encontro das concepções construtivistas de ensino/aprendizagem. As autoras continuam: "O designer não projeta um objeto material, mas um conjunto de interações", sendo o ambiente educacional "um conjunto de possíveis interações e não um sistema com resultados definidos. A meta de um designer que atua no campo da Educação é promover um processo mental, denominado aprendizagem, o qual não se pode mensurar e nem predizer" (p. 18).

Apesar de não se poder mensurar e nem predizer a aprendizagem, conforme a proposta destas autoras, com o auxílio do Design espera-se potencializar o aprendizado e projetar experiências. Isto não significa dizer que o aprendizado anterior a aplicação do Design não seja bom ou que o modelo atual não funcione para o aprendizado, mesmo porque as escolas têm cumprido seu papel há muito tempo e possuem didáticas que tiveram e têm sucesso e méritos indiscutíveis, mas sim, que existe uma demanda por novos produtos, e que o Design pode auxiliar na configuração destes.

Para este artigo, se faz necessário, além de definir o que se entende por Design, definir a forma de abordagem que se está propondo para a configuração das animações educacionais. O Design Centrado no Usuário (DCU) pode ser definido como projeto que possui foco, direcionamento e base nas questões relativas ao usuário. Ele é entendido como o projeto que direciona todo o processo realizado para confeccionar o produto ao atendimento das necessidades do usuário final (ROYO, 2008). Nesta perspectiva têm-se um estudo ampliado dos contextos relacionados à utilização dos materiais.

O Design Centrado no Usuário possui um histórico comum às linhas construtivistas, influenciado pelas teorias soviéticas de Vygotsky e pela Teoria da Atividade de Leontiev (LEONTIEV, 1979) com inserção do contexto e das relações sociais como requisito de projeto. 
Os princípios de DCU utilizados nesse artigo têm base na proposta de Maguire (2001). Estes princípios são advindos da área de Interação Humano-Computador (IHC), onde estão direcionados à construção de interfaces gráficas interativas. Considerou-se que a animação como um objeto de aprendizagem digital, atua dentro de um contexto e possui uma interface que faz ponte entre aprendiz e conteúdo. Pode-se justificar a escolha do autor proposto e acatar os princípios e as características de DCU, apresentados a seguir, como forma de inserir o contexto de uso do material no planejamento de animações:

1. As atividades de DCU prezam pelo envolvimento ativo do usuário por meio da compreensão clara da tarefa e dos requisitos para a sua realização. Este envolvimento necessita de conhecimento amplo do contexto do usuário e da tarefa. Portanto, engloba a pesquisa de requisitos do usuário, da tarefa e do contexto;

2. Distribuição adequada de funções entre usuário e sistema. A determinação das tarefas adequadas às pessoas e aos sistemas pode proporcionar um melhor ajuste de ambos. Isso demanda análise das tarefas que a pessoa pode fazer e as tarefas que seriam mais interessantes que elas não fizessem, atribuindo-as ao sistema. Isso pode ser feito por meio do envolvimento do usuário no processo de Design;

3. Iteração de soluções de Design. Os softwares ou sistemas podem ser testados com seus usuários finais já no início de seu projeto, em forma de protótipo ou mock-ups a fim de detectar problemas ou identificar melhorias. Estas soluções retornam aos designers que as avaliam e geram novas propostas, agregando as ideias colhidas neste teste. A quantidade de testes é ilimitada e o processo de iteração pode ocorrer quantas vezes for necessário para o aprimoramento do produto;

4. Equipe multidisciplinar. Uma equipe com diferentes habilidades e conhecimentos proporciona uma abordagem ampla do projeto e estabelece um trabalho colaborativo acerca do produto/projeto. A equipe pode ser formada por especialistas, usuários, engenheiros, designers gráficos, de usabilidade e de interação, enfim, deve-se dispor de uma equipe constituída de profissionais em quantidade e diversidade adequada às atividades de análise e de projeto das características e funções dos produtos.

Maguire (2001) ainda apresenta alguns benefícios que seriam gerados a partir da aplicação dos princípios. Estes benefícios podem ser assim resumidos: aumento da produtividade do usuário - o sistema foi desenvolvido com e para ele, a partir de suas necessidades, 
habilidades e contextos; redução de erros - a possibilidade de iteração de processos e avaliações auxiliam a detectar as possíveis falhas; redução de treinamento e suporte - o sistema se utiliza das habilidades do usuário, portanto, este já está integrado às suas rotinas; e, por fim, melhor aceitação do material - como o processo de design do sistema tem como base as necessidades do usuário, este se sente mais confiante e apto a utiliza-lo, tendo uma atitude mais positiva ao fazê-lo.

Os processos de DCU podem levar em conta a participação do usuário sob vários aspectos e em quantas fases forem necessárias, sendo esta possibilidade chamada de Design Participativo, uma vertente do DCU. Essa forma de projetar modifica a concepção corrente de design de materiais educacionais, os quais são, geralmente, lineares e sem consulta aos usuários. Muitas vezes as questões do usuário são abordadas por meio dos profissionais que estão executando as tarefas, conforme Sanders e Stappers (2008), o usuário neste processo participa apenas como objeto de estudo e está no projeto por meio do conhecimento do designer/desenvolvedor.

Porém, com a adoção do DCU e do Design Participativo essa posição é modificada, sendo os usuários inseridos nas fases de projeto como participantes ativos (Figura 1). A figura 1 apresenta o caráter cíclico e participativo dos procedimentos de DCU e propõe iterações e testes contínuos. Com isso se tem a introdução do contexto, dos stakeholders, dos objetivos e das necessidades de cada parte. Isto viabiliza o desenvolvimento de um projeto que atenda a diferentes funções e que seja capaz de prever a autonomia ativa dos estudantes, o envolvimento com a atividade, a transmissão do conhecimento por meio de desafios e descobertas e a mediação entre professores, aprendizes e conhecimentos.

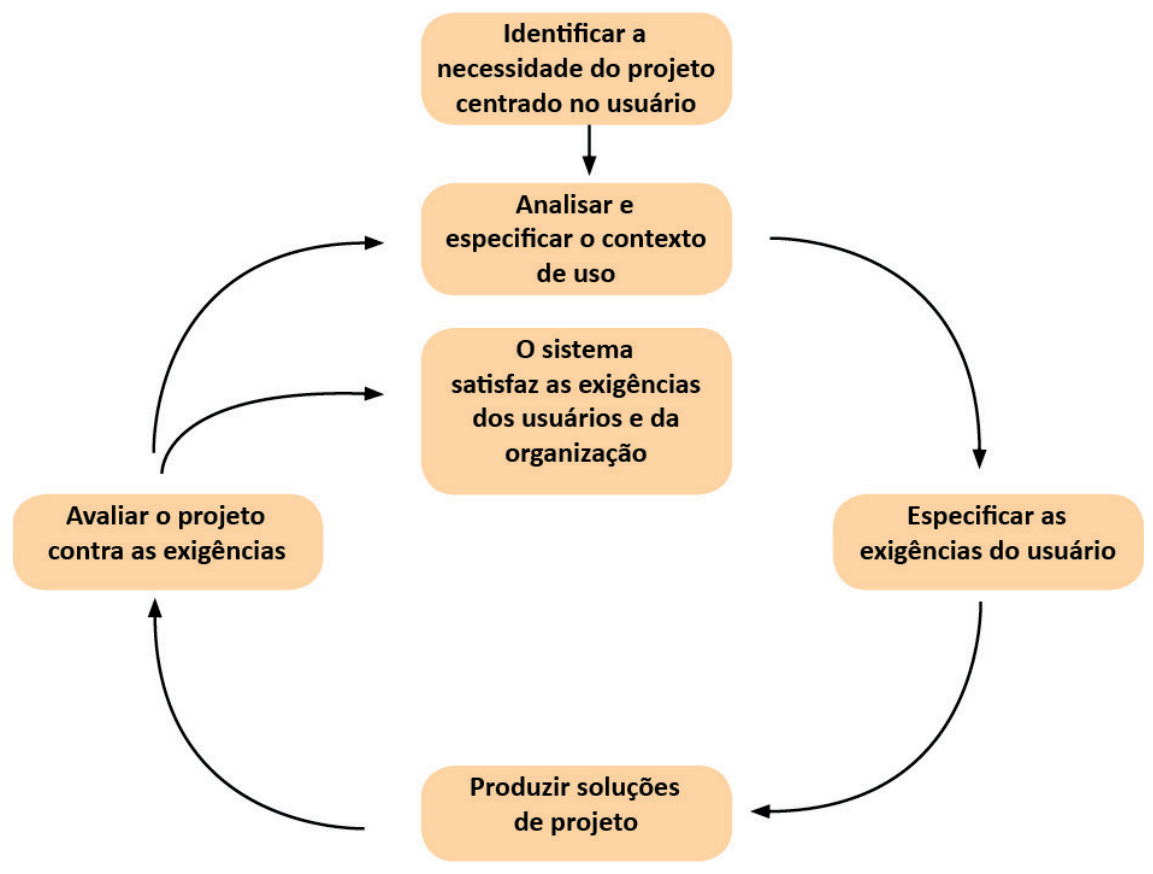

Figura 1 Processo iterativo. (Fonte: ISO 9241-201 (2010)) 
A figura 1 exibe, também, um esquema básico de Design Iterativo e Cíclico proposto pela ISO 9241 (210). Neste esquema cada ação passa por ciclos de especificação de conceito, especificação de requisitos, prototipação e avaliação. Estas fases visam ao atendimento de requisitos e exigências de produção ou para o reinício da atividade caso algo não esteja em conformidade com o resultado esperado.

Cada fase proposta apresenta um conjunto de métodos e técnicas (Quadro 2). Este quadro expõe as fases: de planejamento da atividade e definição de escopo; de contexto de uso, (o que engloba vários contextos possíveis (stakeholders, tarefa, usuários e contextos sociais)); de geração de requisitos para o projeto, com inúmeras possibilidades de pesquisa; do design com a geração de alternativas e protótipos e, por fim; a fase de avaliação, o que envolve os usuários das tarefas/atividades propostas.

Quadro 2 Etapas de DCU e métodos. (Fonte: Adaptado de Maguire (2001))

\begin{tabular}{|c|c|c|c|c|}
\hline Planejamento & Contexto de uso & Requisitos & Design & Avaliação \\
\hline $\begin{array}{l}\text { 1. Planejamento } \\
\text { de Usabilidade } \\
\text { e escopo; } \\
\text { 2. Análise de } \\
\text { usabilidade, custos } \\
\text { e benefícios. }\end{array}$ & $\begin{array}{l}\text { 1. Identificação } \\
\text { dos stakeholders; } \\
\text { 2. Análise do contexto } \\
\text { de uso; } \\
\text { 3. Levantamento } \\
\text { de usuários; } \\
\text { 4. Estudo de campo, } \\
\text { observação de } \\
\text { usuários; } \\
\text { 5. Diários; } \\
\text { 6. Análise da tarefa. }\end{array}$ & $\begin{array}{l}\text { 1. Análise } \\
\text { dos stakeholders; } \\
\text { 2. Análise de custos } \\
\text { e benefícios; } \\
\text { 3. Entrevistas de } \\
\text { requisitos do usuário; } \\
\text { 4. Focus groups; } \\
\text { 5. Cenários de uso; } \\
\text { 6. Personas; } \\
\text { 7. Sistemas já } \\
\text { existentes/ } \\
\text { competidores; } \\
\text { 8. Mapeamento das } \\
\text { funções da tarefa; } \\
\text { 9. Alocação de funções; } \\
\text { 10. Requisitos do } \\
\text { usuário, de usabilidade e } \\
\text { da organização. }\end{array}$ & $\begin{array}{l}\text { 1. Brainstorming; } \\
\text { 2. Design Paralelo; } \\
\text { 3. Design de diretrizes } \\
\text { e modelos; } \\
\text { 4. Storyboards; } \\
\text { 5. Diagrama } \\
\text { de afinidades; } \\
\text { 6. Card sorting } \\
\text { 7. Prototipagem em } \\
\text { papel; } \\
\text { 8. Prototipagem } \\
\text { em Software; } \\
\text { 9. Wizard-of- } \\
\text { Oz prototipagem; } \\
\text { 10. Prototipagem } \\
\text { organizacional. }\end{array}$ & $\begin{array}{l}\text { 1. Participativa; } \\
\text { 2. Assistida; } \\
\text { 3. Avaliação; heurística } \\
\text { de especialistas; } \\
\text { 4. Testes controlados; } \\
\text { 5. Questionários } \\
\text { de satisfação; } \\
\text { 6. Avaliação de } \\
\text { trabalho cognitivo; } \\
\text { 7. Incidentes críticos; } \\
\text { 8. Entrevistas pós- } \\
\text { experiência. }\end{array}$ \\
\hline
\end{tabular}

As fases e técnicas dispostas no quadro 2 necessitam de constante adaptação para atender as necessidades de cada interface e de cada projeto. Com isso, busca-se obter o maior número possível de requisitos para o design da atividade ou da tarefa por meio do entendimento do contexto/usuário.

Como se pode observar, o DCU estabelece algumas técnicas e um processo que pode auxiliar na confecção de materiais educacionais sob o viés construtivista. Isso se deve ao fato de ter como base o contexto e a colaboração no processo de execução das atividades. Essas conexões serão abordadas com mais profundidade no próximo tópico. 


\section{Conectando princípios}

Os objetivos e os princípios das atividades construtivistas estão pautados no conceito de conhecimento como descoberta constante e da experimentação em ambientes colaborativos. São objetivos construtivistas: a autonomia na aprendizagem, a problematização aberta pautada nas descobertas dos aprendizes, a possibilidade de reflexão, o domínio compartilhado das tarefas, a busca por desafios, a modelagem de habilidades sociais e individuais com ênfase nos contextos e na geração de situações de aprendizagem (FILATRO, 2008).

Ao comparar os objetivos das concepções construtivistas com os princípios básicos de DCU propostos por Maguire (2001) que são: envolvimento ativo do usuário, compreensão clara da tarefa e dos requisitos para a realização, a distribuição adequada de funções entre usuários e sistemas, processo iterativo, e equipes multidisciplinares, percebe-se que ambas as linhas têm princípios semelhantes (pois estes advêm da mesma base teórica) e têm como base a interação e o envolvimento do usuário/aprendiz com o produto/atividade que estão criando ou realizando. E, mais do que o conhecimento das questões cognitivas de aprendizagem, por meio do DCU, leva-se em conta os contextos e cenários de uso das interfaces.

A figura 2 apresenta uma comparação das teorias e demonstra uma possível ligação entre os objetivos de cada uma delas. No entanto, como já dito na introdução deste artigo, os contextos que cada teoria trata são diferentes. O DCU prevê um contexto mais fechado com a tarefa e o construtivismo busca um contexto mais amplo com fatores ligados a investigação intensa dos usuários/aprendizes. O DCU entra como um processo sistematizado para atingir, ao menos nas questões de uso, a adequação da tarefa ao aprendiz.

Ao considerar a animação como objeto de aprendizagem que precisa ser configurado com foco na experiência e no contexto do aprendiz, se nota uma aproximação do processo de design deste produto com as práticas de projeto de interfaces e de produtos centradas no usuário.

Ao pautar os requisitos de criação da atividade no aluno, somados ao levantamento de seus outros contextos (sociais, culturais e etc.), pode-se criar atividades colaborativas, desafios apropriados, modelagens de habilidades e reflexões que vão ao encontro dos contextos e repertórios do aprendiz.

A análise das tarefas, uma atividade característica dos princípios de DCU, proporciona uma distribuição adequada de funções entre usuários e sistemas. Esse princípio pode ser considerado essencial às concepções construtivistas, pois tende a analisar a atividade de maneira minuciosa e a dividir responsabilidades, o que gera interações adequadas entre os sistemas, objetos de aprendizagem e os aprendizes. Este princípio se alinha às questões de modelagem, pois, por meio do DCU, modela-se a atividade conforme as habilidades dos usuários por intermédio de consultas, testes e iterações. 
Como o DCU prioriza o objetivo claro e as margens para a iteração com o envolvimento dos aprendizes desde o início do processo de design, ele pode prevenir erros, ajustar as atividades e tarefas com testes e administrar a experiência do aprendiz.

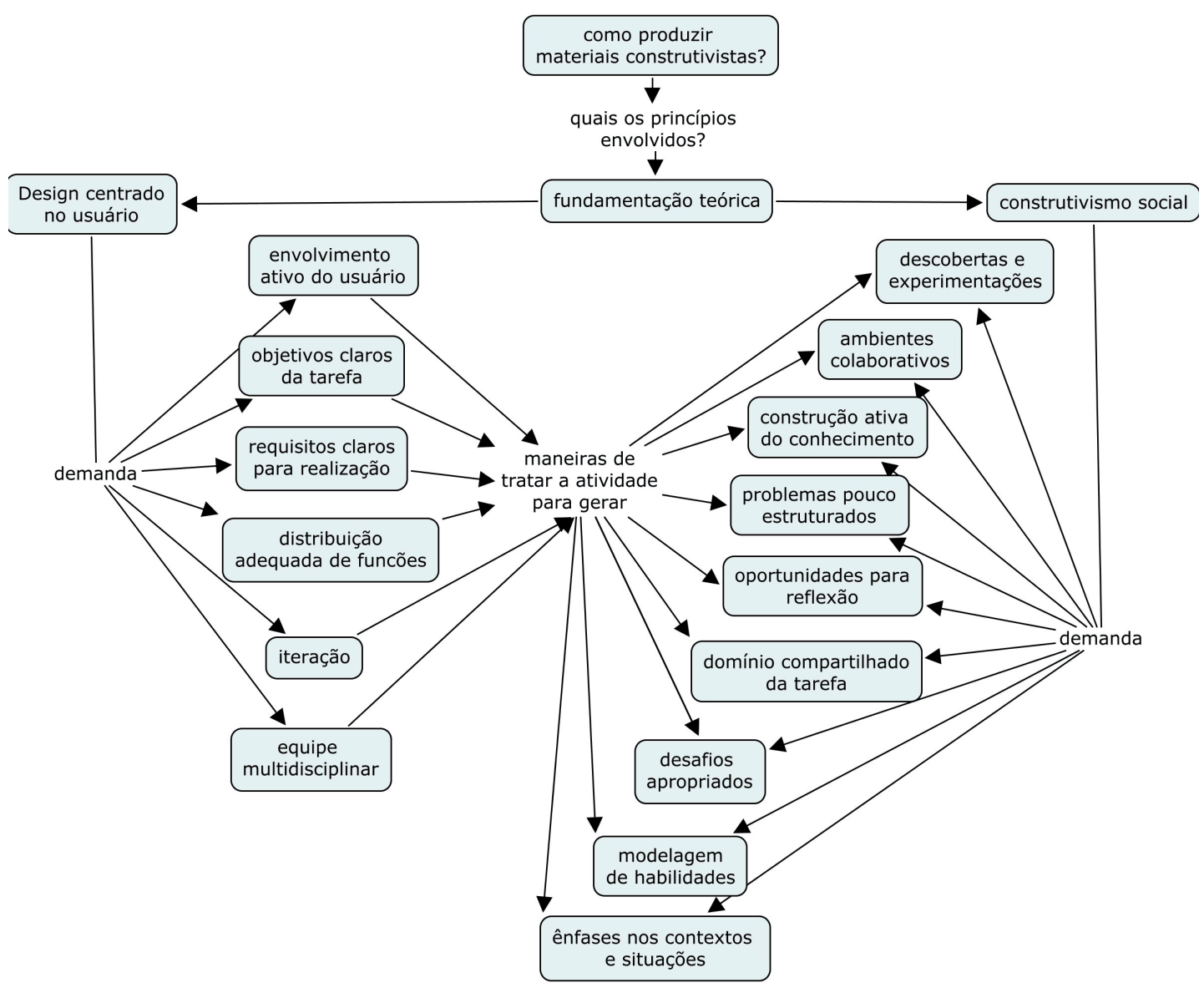

Figura 2 Relações possíveis de princípios construtivistas com o DCU

(Fonte: Adaptado de Filatro (2008) e Maguire (2001))

Por fim, o DCU sugere equipes multidisciplinares de trabalho. Essas equipes podem ser necessárias quando se deseja proporcionar situações de aprendizado e atingir os diferentes contextos dos aprendizes. Por isso, a atividade ou o conhecimento pode exigir habilidades específicas da área do Design, da Psicologia, da Didática, das Neurociências, da Antropologia e das Licenciaturas. Tal atividade só pode ter alcance significativo se os seus aspectos forem analisados e estudados, tarefa que não caberia a uma única pessoa desenvolver, mas, sim, a uma equipe que trabalharia de forma colaborativa (Figura 3). 
Construtivismo (princípios/objetivos):

Descobertas, experimentação;

Atividades e ambientes colaborativos;

Construção ativa do conhecimento;

Problemas pouco estruturados;

Oportunidades de e para reflexão;

Domínio compartilhado de tarefas;

Desafios apropriados;

Modelagem de habilidades (individuais e sociais);

Ênfase nos contextos e situações de aprendizagem.
DCU (princípios/características):

O envolvimento ativo do usuário;

Compreensão

clara da tarefa e dos

requisitos para a realização;

Maneira de

alcance dos Distribuição adequada de

objetivos

funções entre usuários e sistemas;

Iteração de soluções de design;

Equipe multidisciplinar de design.

Figura 3 Conexões entre o DCU e o construtivismo. (Fonte: Adaptado de Maguire (2001) e Filatro (2008))

Por apresentar estes princípios e benefícios, o DCU pode permitir melhor alinhamento das atividades e sistemas gerados para a área de educação. O DCU busca maior conhecimento do usuário em seu próprio contexto (da tarefa) para a realização de determinada atividade com um objetivo claro, com isso pode auxiliar na construção do conhecimento e das tarefas dentro de uma concepção pedagógica. A participação dos aprendizes na conceituação destes materiais pode ser um elemento chave para a criação de materiais conectados com o usuário, o que pode proporcionar a aprendizagem significativa.

O DCU propõe um processo pautado em análise, síntese e avaliação constante o que pode auxiliar no projeto das situações de aprendizado. Quase todas as propostas apresentadas por Maguire (2001) podem ser utilizadas em um processo de confecção de uma animação. O processo proposto pode abranger as animações de maneira mais ampla e interligada com as questões contextuais de aprendizes e professores. Espera-se, com o uso do DCU na confecção de animações, que estas possam ser melhor compreendidas pelos estudantes e melhor utilizadas em salas de aula.

A Figura 4 apresenta um processo de animação (com base em MARX (2007) e LAYBOURNe (1998)) com a inserção de um procedimento cíclico na fase de concepção das animações educacionais, envolvendo professores, alunos e designers na confecção dos materiais. Este esquema projetual permitiria prever o contexto, analisar a tarefa a ser realizada, o objetivo a ser alcançado, o envolvimento que será proporcionado ao aluno e a autonomia que a atividade poderá evocar dentro da sala de aula. 


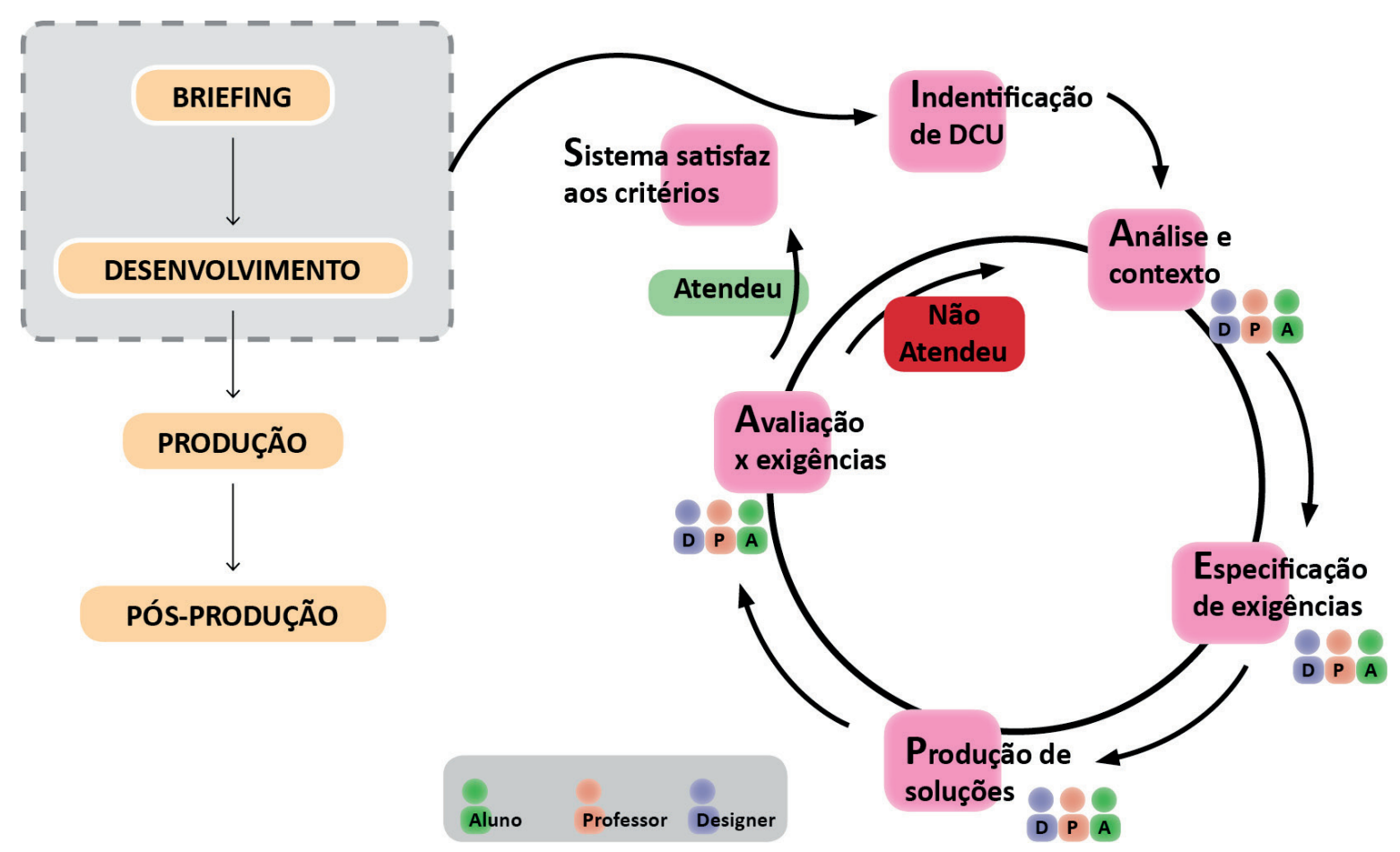

Figura 4 Animação projetada com inserção do DCU, processo participativo e cíclico (Fonte: Adaptado de Maguire (2001), Marx (2007) e Laybourne (1998))

Os ciclos de análise, síntese e avaliação das atividades de DCU podem proporcionar base mais sólida de trabalho para os desenvolvedores. Isso pode evitar perdas e custos para o produtor e proporcionar situações de aprendizagem mais adequadas para o aluno.

\section{Considerações finais}

O DCU e as práticas construtivistas de ensino possuem uma raiz conceitual semelhante. No entanto, sua utilização na solução de materiais educacionais ainda é incipiente. Custos, tempo e culturas ampliam o distanciamento entre estas práticas. A proposta de junção do Design com a Educação na formação de objetos de aprendizagem não é nova, ela já foi utilizada por pesquisadores como Fontoura (2002) que propõem não só o DCU como abordagem para prática educativa, mas sim, o próprio pensamento em Design e suas práticas como forma de ensino; e Portugal (2013), que propõe um processo abrangendo muitas das técnicas de DCU para a geração de materiais para Educação.

A organização das tarefas e a busca de requisitos e diretrizes advindas do usuário e de seus contextos podem auxiliar no maior entendimento dos aprendizes e no melhor ajuste dos materiais projetados para o ensino com as questões relacionadas às concepções pedagógicas. O processo de DCU contribui para o Design da Informação, da aprendizagem e da motivação, ou seja, com a experiência do aprendiz com o conteúdo. Além do que suas técnicas 
e princípios podem ser uma maneira de facilitar a aplicação dos ideais construtivistas, envolvendo os usuários e prevendo tanto interações que venham a ser realizadas quanto possíveis erros de projeto.

Este estudo partiu de um desdobramento da dissertação do primeiro autor que pretende, como trabalho futuro, a geração de um modelo de Design para animações centradas no usuário visando à motivação dos aprendizes. Espera-se empregar os conhecimentos de DCU na configuração destas animações.

Sugere-se como continuação para esta pesquisa a inserção de mais pensadores interacionistas, pois, este estudo se restringiu às questões propostas pelo construtivismo de Vygotsky. A inserção de outros olhares pode ampliar a discussão aqui iniciada.

\section{Agradecimento}

Ao financiamento da Bolsa CAPES.

\section{Referências}

Alves, M. M.; Battaiola, A. L. (2012). Design de animações educacionais: recomendações de conteúdo, apresentação gráfica e motivação para aprendizagem. Dissertação, Curitiba: UFPR.

AInsworth, s. (2008). How do animations influence learning? School of Psycology and Learning Sciences Reserch institute, UK: University of Nottingham.

BARbOSA JÚNIOR, A. L. (2005). Arte da Animação: técnicas e estética através da História. 2. Ed. Senac: São Paulo.

BRAGA, M. DA C. (2011). O papel social do design gráfico: história, conceitos \& atuação profissional. São Paulo: Ed. SENAC.

Filatro, A. (2008). Design instrucional na prática. São Paulo: Pearson Education do Brasil.

FONTOURA, A. M. (2002). EdaDe: a educação de crianças e jovens através do design. Tese de Doutorado. Florianópolis: UFSC.

FLUSSER, v. (2007). O mundo codificado: por uma filosofia do design e da comunicação. Org. Rafael Cardoso. São Paulo: Cosac Naify.

FREIRE, P. (1996). Pedagogia da autonomia: saberes necessários à prática educativa. São Paulo: Paz e Terra (Coleção Leitura).

Goodwin, K. (2009). Designing for the digital age: how to create human-centered products and services. Indianapolis: Wiley Publishing.

ISO 9241-210. (2010). Ergonomics of human-system interaction - Part 210: Humancentred design for interactive systems.

KENSKI, v. M. (2007). Educação e Tecnologias: o Novo Ritmo da Informação. Campinas, SP: Papirus.

LAybourne, к. (1998). The Animation Book: A Complete Guide to Animated Filmmaking-From Flip-Books to Sound Cartoons to 3-D Animation by. New York: Three Rivers Press, 1998. 
LEONT'EV, A. N. The problem of activity in Psychology. In WERTSCH, J. V. (ed.) The concept of activity in Soviet psychology. New York: M. E. Sharpe, 1979.

LOWE, R. ET AL. (2008). Learning with Animation: Research Implications for Design.

USA: Cambridge University Press.

LÖвАCH, в. (2001). Bases para a configuração dos produtos industriais. São

Paulo: Blucher.

MAGUIRE, M. (2001). Methods to support human-centred design. Int. J. Human-

Computer Studies, vol 55, 2001.

MARX. C. (2007). Writing for animation, comics and games. UK: Focal Press.

MOREIRA, M. A. (2006). A teoria da aprendizagem significativa e sua implementação em sala de aula. Brasília: Universidade de Brasília.

PORtugal, c. (2013). Design, educação e tecnologia. Rio de Janeiro: Rio Books.

PORTUGAl, C; COUTO, R. (2010). Design em situações de ensino e aprendizagem. In:

Estudos em Design. Volume 18.1, 2010.

SANDERS, E. B.; STAPPERS, P. J. (2008). Co-creation and the new landscapes of design.

CoDesign, vol 04, no 01, p. 05-18.

SANT'ANNA, I. M.; SANT'ANNA, V. M. (2004). Recursos educacionais para o ensino -

quando e por que?. Petrópolis: Vozes.

ROYO, J. (2008). Design digital. 1a. Ed. São Paulo: Rosari.

\section{Sobre os autores}

\section{Marcia Maria Alves}

<alvesmarcia@gmail.com>

Doutoranda em Design do PPGDesign da UFPR, pesquisa animações educacionais e design voltado para educação.

\section{André Luiz Battaiola}

<ufpr.design.profe.albattaiola@gmail.com>

Professor do Departamento de Design da UFPR. Bacharel em Física pelo IFUSP. Mestre e Doutor em Engenharia Elétrica (EPUSP). PósDoutorado pelo SSEC da University of Wisconsin.

Artigo recebido em 09 dez. 2013, aprovado em 02 jul. 2014. 